\title{
Other Spaces of the Empire: A Colonial Hotel in J.G. Farrell's Troubles
}

\section{Tijana Parezanović}

Focusing on the hotel imagery and, more precisely, the hotel Majestic featured in F.G. Farrell's 1970 novel Troubles, this article provides a spatial contextualization of the historical downfall of the British Empire. In an attempt to establish the concept of the "colonial hotel", this particular type of hotel is theorized as a fictional means of questioning the sustainability of the imperial project of colonialism. The theoretical framework for considerations of the Majestic in Troubles as a representative of the "colonial hotel" concept is based on Foucault's heterotopology, as well as on the concepts of liminality and dislocation taken from postcolonial studies. Reading Troubles as an allegory of the Troubles in Ireland and, more broadly, a symptom of the disintegration of the British Empire, the article showes that the hotel, modelled after the historical concept of the Anglo-Irish big house, provides a proper setting where the deconstruction of the binary oppositions of colonial discourse can be played out. While the Majestic represents a mirror-image of the imperial centre, or rather a dislocated centre, its destruction is brought about by its tendency towards constancy and perpetuation of the illusion of grandeur. Similarly, the British Empire refuses to acknowledge the socio-political and historical changes of the early twentieth century and denies the existence of interstitial spaces between its firmly defined structures, whereby it inevitably meets its end.

\section{Keywords}

Hotel; heterotopia; Troubles; big house novel; British Empire; dislocation; liminality; centre/periphery

\section{Introducing Fictional Hotels and Hotel Fiction}

Although the basic idea behind hotels, both real and fictional, is to offer the kind of comfort and intimacy that can only be found at one's home, the fact that they have quite frequently appeared in fiction as the setting in crime and horror narratives indicates a certain kind of anxiety which pervades these purportedly homely places. The list of such narratives is rather long: to name 
a few examples, one could probably refer to the more well-known Agatha Christie's Evil under the Sun (1941) or At Bertram's Hotel (1965), Robert Bloch's (1959) and later Alfred Hitchcock's (1960) Psycho, or Stephen King's The Shining (1977). Stephen King himself, in the brief introduction to "1408" - a hotel room story or, as he terms it, a "story about the Ghostly Room At The Inn" (365) - explains this hotel-induced anxiety as a manifestation of the fear one experiences if, as a hotel guest, one starts wondering about all the previous occupants of that same room and the possibility of their being sick, mad, or prone to suicidal thoughts. As far as crime fiction is concerned, the tension of the plot involving danger, threat and fear, as well as riddles to be solved and secrets to be either kept or revealed, finds an appropriate setting in any hotel, where people can, having detached themselves from the familiarity of their usual surroundings, assume any identity and thus contribute to the clandestine nature of crime ${ }^{1}$.

Such tensions and anxieties invoke the sensation of the uncanny, which, according to Martin Heidegger, suggests the "un-homely" experience and "means "not-being-at-home" (Tally 66) ${ }^{2}$. While the uncanny is an effect most usually associated with Gothic fiction, it does not go unnoticed in the whole body of literature and films in which hotels play an important part, and where the sense of anxiety and uneasiness is produced by the obvious fact that the hotel, though it strives to imitate home as much as possible, can only serve the transient guest whose constant awareness of non-belonging to the hotel space frequently brings to light other identitary or social crises. Thus, regardless of whether the hotel appears as an urban place distinctively associated with the modern city (as, to name a few examples, in Liliana Cavani's 1974 film The Night Porter, partly in Elizabeth Bowen's 1938 novel The Death of the Heart, or Henry Green's 1939 Party Going), or as a tourist resort often located in remote or rural areas (Elizabeth Bowen's 1927 The Hotel, Anita Brookner's 1984 Hotel du Lac, Alessandro Baricco's 1993 Ocean Sea, Alan Moore's 2006 graphic novel Lost Girls, or James Gordon Farrell's 1970 Troubles, which will be used for analysis in the present article), it provides the stage where various opposing forces, conflicts and struggles can be played out. The initial conflict between the familiar and unfamiliar, or else between "the excitement of travel" and "the terror of unknown and unknowable spaces", further extends to "the tension between opposites: claustrophobia and exhilaration, the public and the private, alienation and inclusiveness, freedom and inhibition" (Pready, "Liminality in a London Hotel"). 
As the above listed examples show, the hotel setting also pertains to genres other than crime and horror fiction - if the examples can be strictly confined within a single genre - including fantasy fiction, coming-of-age stories, trauma narratives or, as in the case of J.G. Farrell's Troubles, what can broadly be referred to as postcolonial writing. Joanna Pready in fact argues for the introduction of a specific genre of "hotel fiction" ("The Power of Place" 35) in those cases where the hotel transcends the status of a mere setting and obtains greater spatial significance, its own identity, and an overpowering influence on characters. The events in hotel fiction "occur because of the hotel" and the hotel possesses spatial dynamics independent of the people who inhabit the place (Pready, "The Power of Place" 34). This approach is undoubtedly relevant for the present analysis inasmuch as it informs the text with a methodological model which allows us to observe the spatial dimensions of Farrell's Troubles as crucial to the development of the story. It could be argued that the hotel world relates easily to postcolonial fiction due to the concept of liminality which characterizes both: it is inseparable from the tensions existing within the hotel space and making it into a boundary zone between clearly defined opposites (such as "homely" and "un-homely"), while it also serves as one of the critical concepts used by Homi Bhabha to define the post of post-colonialism and other post- movements as "the moment of transit where space and time cross to produce complex figures of difference and identity, past and present, inside and outside, inclusion and exclusion." (1) Set in the Ireland of 1919 to 1921, at the time of the Irish War of Independence, Farrell's Troubles - the first novel in what is generally known as his "Empire Trilogy" - deals precisely with the problems of cultural and national identity in a place where defining oneself as either Catholic or Protestant, Nationalist or Unionist, Irish or British, has always been of extreme importance. The novel focuses on a significant moment in the history of Ireland, when the long and not entirely inoppressive British rule is being countered by a vigorously fresh call for liberation and autonomy, and features the Majestic Hotel, owned by the Anglo-Irish Protestant family of Edward Spencer, as the backdrop to, and/or a participant in, dramatic public and private stories which eventually converge in the final destruction of the Majestic.

Relying primarily on Foucault's tentatively proposed heterotopology ("Of Other Spaces" 24) and borrowing from postcolonial studies theoretical concepts such as liminality and dislocation, this article will examine the ways in which Troubles provides a spatial framework for the gradual historical 
downfall of the British Empire. Using the imagery of the Majestic from Troubles, the article aims to establish the concept of the colonial hotel, a type which serves as the appropriate locus for theorizing the unsustainability of imperial dominance, primarily due to the dynamics of departures and arrivals which is closely related to the liminality of the hotel space, and inherently inconsistent with the imperial project of colonialism.

\section{The Theoretical Hotel, and Other Spaces}

In a 1967 lecture, later published as the essay titled "Of Other Spaces", Michel Foucault famously proclaimed the twentieth century to be "the epoch of space" (22), stating also his belief that "the anxiety of our era has to do fundamentally with space, no doubt a great deal more than with time" (23). Although this by no means implies that space was completely absent from pre-twentieth-century thought and practice, or otherwise, that history and time bear no relevance whatsoever in the twentieth century and beyond, the immense significance of the early-twentieth-century modernist fascination with the spatial cannot be neglected. Social phenomena such as "a shift from an aristocratic to a bourgeois leisure class" (Matthias 3), urbanization and the growth of cities, or the modernization of transport which in turn facilitated movement and travel, were all distinctive features of the modern experience of life, as well as of modernist literature. Even more importantly for the present analysis, modernism in Europe relied on its colonies and dominions throughout the rest of the world, particularly on "the various journeys across and between 'first world' metropolitan spaces and 'third world' imperial spaces" (Thacker 6), whereby "the interrelationships between the great triad of modernism, the metropolis and imperialism" showed that spatial relations are sustained by the relations of power, manifest in "the occupancy and dispossession of actual geographical locations in the context of national and international politics" (Thacker 6). Published in 1970, Troubles stands at the very crossroads where modernism overlaps with the postmodern, and it is from this vantage point that the novel discusses and negotiates the power-informed spatial relations between imperial Britain and the occupied territories in Ireland immediately before and during the War of Independence. This vantage point being "the present [that] can no longer be simply envisaged as a break or a bonding with the past and the future", but rather the "interstitial passage between fixed identifications" (Bhabha 4) allows for Troubles to question the earlier 
established connection between imperialism and the metropolis as the centre of imperial power, symbolically transferring the imperial centre to an Irish countryside hotel and subsequently describing the process of its ruination.

Although numerous authors have since (and before) Foucault's lecture on other spaces theorized spaces and places from many different perspectives, it seems that the particular character of the hotel has, despite its increasingly significant role in the poetics of everyday life, as well as in a large number of cultural texts, remained insufficiently addressed. One of the rare theoretical contributions can be found before 1967, in Siegfried Kracauer's The Mass Ornament, where the author, while recognizing the power inherent in the hotel space, stresses the void, the nothingness implicit in every element of the hotel. Kracauer compares the hotel to the house of God, both being places where people appear as guests. The hotel is, however, "a negative church" (Kracauer 175) in which the congregation cannot find any spiritual comfort or revelation but rather, being "intent on rationalization," meets its end (178). The silence that pervades hotel lobbies, corridors, and rooms is a symptom of this void, as it "compels one downward into the equality of the encounter with the nothing, an equality that a voice resounding through space would disturb" (Kracauer 181). Farrell's Troubles indeed opens with one such image. On arriving at the Majestic, Major Brendan Archer, who is engaged, through a series of overwhelmingly detailed letters, to the owner's daughter Angela, whom he saw but once, encounters complete silence and the absence of any human form; after contemplating this void for a while, he decides to ring the bell on the reception desk. The silence in the Majestic is, as shall be dealt with in more detail later on, indicative of the decay that has already begun its slow process, both in the hotel and within the Empire. The decay also shows in the images of the "dusty tiled floor", "gloomy carpeted corridors", disintegrating staircase, "a great glass chandelier studded with dead electric bulbs" (Farrell 13). The Major's disturbing agency interrupts this process for the most basic reason that he has recently left hospital, where he was recovering from the unnamed consequences of his participation in the Great War - the decay he witnessed is, namely, far more substantial than the one encroaching upon a mere hotel. As the Major declines the company of his former friends and admits to being "only at ease in the company of strangers" (Farrell 8), it would seem perfectly appropriate for him to seek leisure or oblivion among the anonymity of any seaside hotel where "[r]emnants of individuals slip into the nirvana of relaxation, faces disappear behind newspapers, and the artificial continuous light illuminates nothing but mannequins" (Kracauer 
183). However, what the Major is looking for is some form of the home he no longer has and which he vaguely expects to find by the side of his mysterious fiancée. It is this element of homeliness contained in the promise of a marital union that poses as the major disturbance Brendan Archer brings on the Majestic. It is also at this early point that the hotel in Troubles resists the theoretical conceptualization proposed by Kracauer and requires a reading that might contest Kracauer's void. This again brings us to Foucault's essay "Of Other Spaces", and his observation that "we do not live in a kind of void" (23). Foucault here calls for the study of certain other spaces or heterotopias, which exist as sites physically located in space, although they differ from all the other real sites, and at the same time represent, contest, and invert them (24).

One important characteristic of Foucault's heterotopias is that they are, unlike Kracauer's hotels, spaces which resist desanctification ("Of Other Spaces" 23) and preserve some of the mystery attached to ancient rituals and rites of passage from one clearly defined system into another. Foucault does not list the hotel per se as a heterotopia, but rather makes references to three distinct types of hotels: honeymoon hotels as "crisis heterotopias" (24), vacation villages as a unique mixture of "the heterotopia of the festival and that of the eternity of accumulating time" (26), and the more contemporary concept of the American motel room. However, what is relevant for the present analysis is the basic function of heterotopias as sites of representation, contestation, and inversion of other real spatial entities (the British Empire in the case of Troubles), as well as the set of principles that heterotopias are built on, and which also allow for the Majestic in Troubles to serve as the counter-site to the Empire, thus showing its historical progress and downfall.

\section{The Grand Pre-War Hotel as Heterotopia}

The hotel presented in Troubles is representative of the tradition of "the grand hotel culture of the pre-war years" (Matthias 17). This is sustained by the text from the very first pages, which describes the splendour of the Majestic before Edward Spencer took over the management on his return from India (later specified as the $188 \mathrm{os}$ ). As one of the grand pre-war hotels, the Majestic equally corresponds to the Foucauldian heterotopia. First, it is not dissimilar to the time-accumulating heterotopias, such as museums and libraries, "in which time never stops building up and topping its own summit" (Foucault, 
"Of Other Spaces" 26). The very idea, according to Foucault, of collecting all epochs, forms and tastes, and enclosing them within a single place - of "constituting a place of all times that is itself outside of time and inaccessible to its ravages" - is essentially modern, originating in nineteenth-century western culture (26). Thus the central architectural feat testifying to the former grandeur of the Majestic, the ballroom towered by a vast glass dome, is described by Edward, in a rather long and sentimental monologue, in terms of the abundance of events and experience related to it. Edward speaks of the balls, the carnivals, and the regattas from the period when the Majestic was in its prime, reminiscing about the "violins and glinting chandeliers and silk dresses and an occasional cry of a peacock" (Farrell 63). The very fact that the Major, despite his apparent determination - gained almost immediately after his first arrival - to leave the Majestic, still comes back to the hotel, is yet another indicator of the great attraction the place holds and the varieties - or rather curiosities - it offers, albeit while going through progressive ruination under the Spencers.

The Majestic does not solely comply with the concept of the timeaccumulating heterotopia, but corresponds more generally to the six principles elucidated in Foucault's "Of Other Spaces". Foucault first speaks of the places that have been since time immemorial reserved for those members of society who are in some kind of crisis - "adolescents, menstruating women, pregnant women, the elderly, etc." (24) Thus the Majestic functions as ultima Thule for a number of old-lady guests, Angela's Granny Rappaport, who lives doubly enclosed in a room behind "a small concealed door in the oak panelling" (Farrell 35), and Angela herself, who is dying of leukaemia, confined in one of the many unknown and inaccessible rooms of the hotel. The Major himself is still in a state of crisis due to the consequences of the war. Next, heterotopias can, in accordance with the needs and intents of society at a given period of time, function in different fashions (Foucault, "Of Other Spaces" 25). This principle is most ostentatiously notable in the fact that the old ladies who have now resided at the Majestic for years on end actually transform the hotel into their home. This, as will be discussed further on, stands as one of the crucial factors in theorizing the downfall of the grand hotel, and symbolically of the Empire itself, which implies that the potential for self-ruination is latently present in the very concept of the grand hotel as heterotopia. The multifunction heterotopian principle is, however, not limited to transforming the hotel into home - the place also comes to serve as barracks for the Auxiliaries, members of the police sent from England to 
help the local Royal Irish Constabulary, or as a retreat for Edward Spencer, who sets up a laboratory for his unfathomable biological research in the midst of the above mentioned ballroom.

Foucault's third principle states that "[t]he heterotopia is capable of juxtaposing in a single real place several spaces, several sites that are in themselves incompatible" and refers to places such as the theatre stage or Oriental gardens ("Of Other Spaces" 25). The principle is embodied in Troubles in the imagery of the Palm Court, an important part of the hotel where the traditional five-o'clock tea is served amidst a variety of exotic plants which appear to be out of place in the Irish climate. The Palm Court is "a vast, shadowy cavern in which dusty white chairs [stand] in silent, empty groups, just visible here and there amid the gloomy foliage" of "banana and rubber plants, hairy ferns, elephant grass and creepers that dangled from above like emerald intestines" (Farrell 14). Gathering the vegetation from all around the world in a single place, the Palm Court aspires to the status of a microcosm, "the totality of the world" (Foucault, "Of Other Spaces" 26). Foucault goes on to state that "[ $\mathrm{t}]$ he heterotopia begins to function at full capacity when men arrive at a sort of absolute break with their traditional time" (26). The break records the accumulation of all the times past, while at the same time it marks a standstill in the ordinary flow of time. In this standstill, even Angela's death becomes a timeless state of facts, as perceived by the Major while he listlessly participates in a conversation in the Palm Court: "the old fellow had begun to speak hoarsely, comfortingly, consolingly to Edward of someone who had died [...] that someone was Angela, as if she had only been dead for a matter of hours rather than months" (Farrell 152). It is in accordance with this principle that the original project of the grand hotel as a time-resisting palace, once the unpropitious moment comes, faces its transience and takes on, however unwillingly, its role in "time in the mode of the festival" (Foucault, "Of Other Spaces" 26). One such festival indeed occurs with Edward's attempt to restore the old grandeur of the already dilapidated place by organizing a great ball that should "mark the rebirth of the Majestic!" (Farrell 327). Importantly, Foucault's fifth principle describes heterotopias as "always presuppos[ing] a system of opening and closing that both isolates them and makes them penetrable" ("Of Other Spaces" 26) - such a system is one on which every hotel policy is based, with the guests required to pay for their stay, thus gaining permission to enter the hotel world and assurance that they will not be disturbed in the isolation of their rooms. However, when a hotel such as the Majestic starts falling into disrepair, certain crevices 
and holes appear that might allow for an unpermitted entrance, such as the intrusion of the Sinn Fein members into the Majestic by the end of Troubles. If the only measures taken by the threatened owner remained limited to posting the notice "TRESPASSERS FOUND TAMPERING WITH THE STATUE OF QUEEN VICTORIA WILL BE SHOT ON SIGHT” (Farrell 399), the end of the Majestic could possibly be kept at bay; however, Edward actually shoots a Sinn Fein member, killing him and thus violating the basic principle of hospitality in his hotel.

Last, heterotopias "have a function in relation to all the space that remains", and one of the possible relations is that of compensation, whereby the role of the heterotopia is "to create a space that is other, another real space, as perfect, as meticulous, as well arranged as ours is messy, ill constructed, and jumbled" (Foucault, "Of Other Spaces" 27). Foucault here wonders whether certain colonies could be considered as heterotopian projects, particularly some settler colonies and those from the seventeenth-century wave of colonization. The question that is immediately raised is that of the colonial history of Great Britain and of the troubled relations between the imperial centre and Britain's first colony - Ireland. Ireland is itself presented from the very beginning of Troubles in a pronounced manner of "stereotyped exotic difference" (Ashcroft, Griffiths, and Tiffin 98) and, through the perspective of the returnee Major, as a place of difference, one that forms the perfect other to the Empire: "(All Irish girls are as fat as butter,' thought the Major)" (Farrell 53); "How very foreign, after all, Ireland was!" (54); "The Major smiled when he had read this and thought: "How splendidly Irish!" (69) The question, therefore, which the following section will focus on in some detail, is that of the representation of imperial power in one of the British Empire's colonies. In Troubles, this power manifests in the grand pre-war hotel - itself a heterotopia - which could for this reason be termed a colonial hotel.

\section{The Colonial Hotel: Experience of Dislocation}

One of the fundamental postulates that colonial discourse builds on is the dogmatic validity of binarism and clear separation of elements constituting the binary opposition - a separation which does not approve of any kind of interstitial stage or space between these elements, while at the same time it establishes the dominance of one of them. In terms of (post-)colonial geography and spatial studies, the most significant binary relation is the one between 
centre and margin (or periphery), whereby imperial Europe becomes defined as both the physical and metaphysical centre, and inspired by the colonial mission "to bring the margin into the sphere of influence of the enlightened centre" (Ashcroft, Griffiths, and Tiffin 37). Literary representations of this geographical binary system have in Irish fiction since the early nineteenth century been focused on "the novel of the big house" - a country mansion owned by a Protestant Anglo-Irish family, with the adjacent agricultural land usually leased out to Catholic tenants ${ }^{4}$. These so-called big houses, both real and fictional, were "rural centres of political power and wealth in Ireland", in a way, imperial centres displaced into the Empire's periphery, there to assert "the political and economic ascendancy of a remote colonial power structure" (Kreilkamp 6o). Furthermore, these mansions were, according to Kreilkamp, constructed in such a way as to visually transform parts of Ireland into replicas of England (6o). Thus they metaphorically embodied the centre and, by association, the entire Empire. Such a metaphor is also used to present the Spencers' Majestic in Troubles. Right in front of the hotel entrance, for instance, is a life-size statue of Queen Victoria, the only thing that the Major can, on his arrival, recognize from Angela's letters - thus the only constant at the Majestic. The statue only substantiates the symbolic power of the Majestic, indicating the unquestionable constancy, longevity and domination of the British Empire. Further descriptions of the Majestic refer to its grandeur, another characteristic that connects it with the imperial designs:

After all, the hotel had over three hundred rooms. Even if half the building fell down he would still be left with a hundred and fifty - which was more than enough to house himself [Edward] and the twins and the servants and anyone else who survived the strangulation of the hotel's trade. (Farrell 286)

Significantly, the above quoted passage is directly preceded by a transcript the novel abounds in similar documentary records - of Lloyd George's speech on the current situation in Ireland, in which the Premier ironically refers to Ireland as a disturbed corner of the Empire (Farrell 280). While calling for an armed response to the troubles in Ireland, he does not fail to end his speech with a mention of "Empire at the height of its power $[\ldots]$ in the greatest day of its glory" (Farrell 282). The Majestic, however, reflects a truer state of the already crumbling Empire - one which will continue to provide only for its wealthy citizens and their loyal servants. Though not the owner of 
a family mansion, but a hotel, Edward is still in possession of vast agricultural property in and around the fictional town of Kilnalough, and one of the major conflicts in the novel is the one between him and the tenants who strive to regain possession of the land confiscated from them. Apart from the agricultural land, the grounds on which the Majestic is built also present the hotel as a metaphor for, or rather displaced centre of, the imperial power, as is, for instance, the case with the Majestic's tennis courts, which bear visual resemblance to those of England, and the soil of which, "the draining system and the grass lawn itself had been imported from England, installed specially and with enormous care in order to emulate the heavenly growth that cloaked the courts at Wimbledon" (Farrell 140). At the same time, the metaphorical connection between the Majestic and the Empire strengthens the binary opposition existing between the centre and periphery, with the Irish territories perpetually described in terms of the stereotyped other:

Taking this fact into account it would appear to have been a mistake to dig up the tennis courts (for, in an effort to make the land pay, one or two had been dug up). True, the ones that had been left had forgotten their aristocratic origins and 'gone Irish', the delicate grass becoming thick and succulent in the damp climate, more suitable for feeding cows than hitting forehand drives off. (Farrell 141)

Ireland is thus in the colonial discourse of the Protestant Anglo-Irish family of Edward Spencer constructed as unsuitable for pursuing the aristocrat leisure of playing tennis, and only appropriate for rural or even base (perceived as such within the hierarchical order of binarism) activities such as feeding cows.

What allows for a reconsideration of colonial discourse in Troubles is precisely the fact that the Majestic is not a big house - not simply a home to an AngloIrish family - but a hotel, a space of liminality which is in postcolonial studies in the writings of Homi Bhabha, to be more precise - inseparably linked with hybridity. Liminality and hybridity are prerequisite to the deconstruction of binarism, and they are adequately contextualized within the hotel in Troubles. In addition, the anxiety related to the experience of staying in a hotel causes the same sensation of unhomeliness that is also inherent in the (post-)colonial concept of dislocation, used to "describe the experience of those who have willingly moved from the imperial 'Home' to the colonial margin" (Ashcroft, Griffiths, and Tiffin 73). Although the experience of dislocation can also be attributed to those affected against their will by the colonialism-induced 
circumstances which demand that people create - "in language, in narrative and in myth" (Ashcroft, Griffiths, and Tiffin 73) - a new place out of the space into which they have been transferred, in either case it creates possibilities for the formation of new centres throughout the empire. Thus in Troubles Sarah - a Catholic girl the Major desperately falls in love with after Angela's death - notices teasingly and in a self-parodying mode: "Ah, but the Major wouldn't be interested in all this dull tattle from the provinces since he was in London at the very centre of things, at the very centre of the Empire, of 'Life' even!" (Farrell 115). To this the Major replies with the voice of his disturbing agency: "As for London, though it was indeed the centre of the Empire it was no more the centre of 'Life' than, say, Chicago, Amritsar, or Timbuctoo" (Farrell 117), listing the places he has recently read about in the papers, on account of the conflicts that happened there between the oppressed groups and their oppressors. Chicago, Amritsar and Timbuctoo thus reinforce the significance of the fictional Kilnalough as a place where tensions are played out and stagnant colonial opposites contested. The Majestic as a dislocated centre in Ireland paradoxically serves as both a mirror-image of the imperial political power, and a site of negotiation where it becomes possible for Edward's son Ripon to marry the daughter of the Catholic Noonans, or for a number of Catholic staff to live in the hotel on nearly equal terms as its owners or guests. Again paradoxically, the hotel continues to operate as a home away from home while it steadily becomes more and more dilapidated.

The dilapidation which mirrors that of the Empire provides at this point yet another persuasive argument for observing the grand colonial hotel as a heterotopia. As a metaphorical reflection of the imperial grandeur, the Majestic represents - from the perspective of the centre - a utopian enterprise, "a placeless place" where the Empire at the same time is and is not, just as in the mirror one sees oneself where one is absent (Foucault, "Of Other Spaces" $24)^{5}$. On the other hand, the Majestic - like any mirror - still exists as a site, and it is "[f]rom the standpoint of the mirror [that] I discover my absence from the place where I am since I see myself over there" (Foucault, "Of Other Spaces" 24). Hence the heterotopian aspect of the colonial hotel suggests that those who use it as a mirror-image of the Empire should not be there at all - and both the Major and Edward indeed receive repeated warnings that they should leave Kilnalough as soon as possible: "You must leave Ireland, leave Kilnalough, it's no place at all now for a British gentleman like you" (Farrell 239). 


\section{Ghostly Rooms at the Hotel Colonial}

Heterotopias, as mentioned earlier in this article, arguably contain the potential for self-destruction. This claim is also read from Foucault's introduction to The Order of Things (1966), where he mentions heterotopias for the first time:

Heterotopias are disturbing, probably because they secretly undermine language, because they make it impossible to name this and that, because they shatter or tangle common names, because they destroy 'syntax' in advance, and not only the syntax with which we construct sentences but also that less apparent syntax which causes words and things (next to and also opposite one another) to 'hold together'. (xix, emphasis in the original)

Thus the syntax of the colonial discourse, contained in binary opposites (the syntax that holds the Empire together), can be destroyed by heterotopian places such as hotels. Undermining language is not an infrequent occurrence in Troubles, and can be seen from the very beginning of the novel, for instance, when Angela addresses the Major, who is unaware of her terminal illness: "'Ah, I've been dying' - a fit of weary coughing interrupted her - 'of boredom,' she added peevishly" (Farrell 16). In Angela's letters to the Major, any apparently accidental omission of someone's name undoubtedly means death - the presence of which is only ascertained by means of its unnameability and absence from language. The disruption of order is perhaps most ironically depicted in the detachment of the $\mathrm{M}$ of Majestic from the facade, which nearly kills one of the guests - an old lady recently arrived to spend Christmas there (Farrell 287). The old ladies themselves become entirely interchangeable, with one Mrs Bates leaving only to be replaced by another of the same name, and most of the regular guests forgetting that they are only guests:

Indeed, certain of the old ladies (particularly the Misses Bigley, Archer and Porteous) had lived at the Majestic for so long and in such penurious circumstances that somehow, since Edward no longer felt able to bring up the subject of payment of bills with them, they had metamorphosed themselves into members of the family. (Farrell 175)

Life in the Majestic turning static is the major cause of the downfall of the hotel: metamorphosing into members of the family and turning the hotel into 
their home, the old English ladies directly oppose the dynamics of arrivals and departures. This tendency towards stasis is also relevant for the maintenance of colonial discourse, which aims at keeping the elements of binary oppositions stable and permanent. By refusing or having no opportunity to leave, the ladies of the Majestic perpetuate the historically unsustainable idea of the eternal empire, and spatially locate it at the hotel turned home or centre. As explicated by the text, "[t] here was the simple absurdity of continuing to run the place as a hotel when it had long since ceased to resemble one" (Farrell 408). According to Gaston Bachelard, "all really inhabited space bears the essence of the notion of home" (5) due to the memories it becomes imbued with over time. Referring to this, Bettina Matthias remarks that "hotel rooms can never fulfil our longing for this space [of home]", because "[t]o stay long enough for a hotel room to become such an inhabited space runs counter to the basic idea of hotels as temporary "homes away from home"” (61). This implies that the Majestic cannot retain its grandeur, or even form and structure, once its original purpose has been radically altered. Thus the mirror-image of the imperial Home becomes unhomely, or rather uncanny, coming to resemble a haunted house more and more as it rapidly falls into pieces, with "the wooden blocks of parquet flooring bulg[ing] ominously upward" (Farrell 275) and roots from the Palm Court trying to force their way into the hotel lobby. The Palm Court roots - "those wretched tropical things" (Farrell 276) - mock Edward's earlier efforts to slash away at the foliage gone "wild" with a bread-knife, while the Major observes "that he had never in his life seen indoor plants 'succeed' so well" (Farrell 149) - these indoor plants alluding, in the extremely allegorical language of Troubles, to Britain's internal colony of Ireland ${ }^{6}$. Indeed, as the Majestic becomes increasingly dangerous, the old Spencers' Irish servant Murphy is the only one who knows his way about: "(nobody, not even the twins, not even Edward himself, knew the geography of that immense rambling building better than Murphy who had spent his life in it)" (Farrell 184). It is also Murphy who will light the final match and burn the place down, destroying the last remnants of the British rule over Kilnalough.

Edward's final efforts to restore some order and semblance of grandeur to the Majestic prove futile, possibly because they are based on yet another, however grotesque, massacre. In order to host a magnificent Spring ball at the Majestic - which nevertheless turns out to be disastrous, with even the music "grown hysterical, haphazard, a discordant scraping of violins" (Farrell 356) - Edward takes the Major on a killing spree, shooting the hundreds 
of cats that have over the years proliferated and taken over the Imperial Bar - similarly to the plants that have taken over the Palm Court - and "[a]ll this made a dreadful mess: blood on the carpets, there for ever, ineradicable, brains on the coverlets, vile splashes on the walls and even on the ceiling" (Farrell 330).

Edward's futile efforts at restoring the hotel's glory and his subsequent insensible armament and shooting at any Irishman who dares approach the Majestic are accompanied by references to him as an apparition: "[he] continued to move through the house, treading softly as a ghost, staring and staring, his heart beating strongly, his eyes full of tears" (Farrell 327). This imagery stretches also onto the other remaining inhabitants of the Majestic, who now "flitted [through the corridors] like ghosts, gasping feebly" (Farrell 433), and reinforces the transformation of the Majestic into a haunted house, although this metaphor extends even further. Being a dislocated centre and a mirror-image of the imperial one, the Majestic shows, in accordance with the theoretical outlines of the Gothic locus of the old house, encumbered with "heavy historical trappings" which return in the present as "fears and anxieties" (Botting 2), that the Empire is itself haunted by its history of massacres and injustices committed around the world. As such anxieties find their best expression at the times of various social changes, "political revolution, industrialisation, urbanisation, shifts in sexual and domestic organisation, and scientific discovery" (Botting 2), Troubles on the whole and through the particular hotel world of the Majestic show the centrality of the 1920 s turbulences in Ireland to the final downfall of the great British Empire?

\section{Hotel and the Downfall of the Empire}

The troubles in Ireland, however, were not the sole cause of the collapse of British imperial power. The impossibility of British colonial dominance, a project conceived on such an enormous scale, lies rooted in the very essence of the project: the geography of the Empire and its vast spaces do not allow for the existence of a single centre. The centre is thus necessarily dislocated, even multiplied, and dislocation breeds apprehension and anxiety.

Farrell's Troubles employs the hotel imagery to represent the gradual process of the disintegration of the British Empire precisely because the hotel world is deeply imbued with the experience of anxiety. This experience in the case of Troubles stems from the fact that the owners of the Majestic attempt to create 
an image of their English Home - the imperial centre - within the space of the hotel, which is a project doomed to failure because hotels cannot, after all, entirely replace the comfort of home. While the initial function of the Majestic as a grand hotel in the Irish countryside is to visually represent the power of the Empire - a function rather similar to the one performed by the Anglo-Irish big house - and construct a sharp contrast between the sophisticated centre of the Empire (England) and its rural periphery (Ireland), its very existence diminishes the power of the centre, which it emulates and thus undermines. The Majestic has for this reason been referred to in this article as a colonial hotel and, within the theoretical framework of spatial studies, it is its heterotopian nature that empowers the hotel to herald the downfall of the British Empire. The Majestic represents the British Empire, primarily through its grandeur that is slowly vanishing; it contests the Empire by creating the possibility for people of different national and religious backgrounds to live under the same roof; and finally inverts it as it becomes a ruin. Just like Major Brendan Archer, who disturbingly comes to admit that there are centres of Life other than London, thus questioning the colonial discourse which rejects any idea of the kind, the Majestic, which he grows strongly attached to, contains the potential to disrupt and finally destroy the system of rules that colonial discourse is based on. The most important rule being that of maintaining constancy at all costs, the hotel world - such as the one presented at the Majestic - easily problematizes the unsustainability of colonial discourse due to its liminality, indicating that what one perceives as grandeur and stability is often a mere illusion.

\section{Notes}

1. Agatha Christie makes note of this in At Bertram's Hotel, where Selina Hazy, a friend of Miss Marple, is "always so anxious to recognize people she knew ... and how often she was mistaken and they weren't the people she thought they were" (231). Confused identities and disguises are also employed as motives in Evil under the Sun.

2. The feeling also termed as "not-at-home-ness" by Ashcroft, Griffiths, and Tiffin (73).

3. The other two novels in the trilogy are The Siege of Krishnapur (1973) and The Singapore Grip (1978). Farrell's trilogy marks "key moments in the dissolution of the British empire" (Kreilkamp 75).

4. Most of these mansions were in effect built on land confiscated from Catholic families during the sixteenth and seventeenth centuries (Kreilkamp 6o). During the revolutionary 1920 , more than two hundred of these houses were burnt down "as alien presences in the Irish landscape" (Kreilkamp 72), which is recorded in the literature of the period (for example, Elizabeth Bowen's (1929) The Last September), as well as in the novel by Farrell analyzed here. 
5. The mirror perhaps provides the crucial link between Foucault's heterotopia and the hotel world. It is singled out as one of the stock elements of hotel culture and fiction (Matthias 62). The mirrors in the Majestic are, on the other hand, among the signifiers of the hotel's downfall, as they "had become more fogged and grimy than ever" (Farrell 287).

6. As a mere example of the allusiveness and allegorical quality of the novel, the words of Dr Ryan are offered, addressed to Sarah who at the beginning of the novel is unable to walk: "'If you weren't so spoiled you'd be out of that chair the whole time. You could walk perfectly well ifyou took the trouble. And as for you, Major, perhaps you'd be kind enough to tell Edward Spencer from me to stop aggravating his tenants or there'll be trouble" (Farrell 55-56; emphasis added).

7. The novel makes repeated references to social changes other than the political revolution of Irish Nationalists: apart from Edward's infatuation with scientific work, characters such as Sarah, the twins Faith and Charity, or their friend Padraig, openly manifest the release of thus far repressed sexuality and sexual liberties.

\section{Works Cited}

Ashcroft, Bill, Gareth Griffiths, and Helen Tiffin, eds. Key Concepts in PostColonial Studies. London: Routledge, 1998. Print.

Bachelard, Gaston. The Poetics of Space. 1958. Trans. Maria Jolas. Boston: Beacon Press, 1994. Print.

Bhabha, Homi. The Location of Culture. London: Routledge, 1994. Print.

Botting, Fred. Gothic. 1996. London: Routledge, 2005. Print.

Christie, Agatha. At Bertram's Hotel. 1965. London: Perfect Bound, 2003. Ebook.

Farrell, James Gordon. Troubles. 1970. London: Phoenix, 1993. Print.

Foucault, Michel. The Order of Things: An archaeology of human sciences. 1966. London: Routledge, 1989. Print.

---. "Of Other Spaces." Trans. Jay Miskowiec. Diacritics 16.1 (Spring, 1986): 22-27. Web. 24 Nov. 2015.

King, Stephen. Everything's Eventual. New York: Scribner, 2002. Print.

Kracauer, Siegfried. The Mass Ornament: Weimar Essays. 1963. Trans. Thomas Y. Levin. Cambridge, MA: Harvard University Press, 1995. Print.

Kreilkamp, Vera. "The novel of the big house." The Cambridge Companion to the Irish Novel. Ed. John Wilson Foster. Cambridge: CUP, 2006. 6o-77. Print.

Matthias, Bettina. The Hotel as Setting in Early Twentieth-Century German and Austrian Literature: Checking in to Tell a Story. Rochester: Camden House, 2006. Print.

Pready, Joanna. “Liminality in a London Hotel: Henry Green's Party Going and 
the Impact of Space on Identity." Literary London: Interdisciplinary Studies in the Representation of London 7.1 (March, 2009): n.pag. Web. 25 June 2015. --.. "The Power of Place: Re-Negotiating Identity in Hotel Fiction." Diss. University of Nottingham, 2009. Web. 20 Jan. 2016.

Tally, Robert T. Jr. Spatiality. London: Routledge, 2013. Print.

Thacker, Andrew. Moving through Modernity: Space and Geography in Modernism. 2003. Manchester: Manchester University Press, 2009. Print.

TIJANA PAREZANOVIĆ is an assistant professor at Alfa BK University in Belgrade, Serbia, where she teaches courses in British literature, cultural studies and literary translation. Her current research interests include Australian literature, spatiality in modernist and contemporary literature, and popular culture. She is a co-author of three edited books, numerous articles and translations of fiction and non-fiction, and also acts as associate editor of [sic] - A Journal of Literature, Culture and Literary Translation.

\section{tijanaparezanovic@gmail.com}

